Bond University

Research Repository

\title{
An overview of component unit pricing theory
}

Cattell, David William

Published in:

Construction Management and Economics

DOI:

10.1080/01446193.2011.648948

Licence:

Other

Link to output in Bond University research repository.

Recommended citation(APA):

Cattell, D. W. (2012). An overview of component unit pricing theory. Construction Management and Economics, 30(1), 81-92. https://doi.org/10.1080/01446193.2011.648948

\section{General rights}

Copyright and moral rights for the publications made accessible in the public portal are retained by the authors and/or other copyright owners and it is a condition of accessing publications that users recognise and abide by the legal requirements associated with these rights.

For more information, or if you believe that this document breaches copyright, please contact the Bond University research repository coordinator. 


\section{Bond University}

\section{ePublications@bond}

Mirvac School of Sustainable Development

Institute of Sustainable Development and

Architecture

$2-6-2012$

\section{An overview of component unit pricing theory}

David Cattell

Bond University, dcattell@bond.edu.au

Follow this and additional works at: http://epublications.bond.edu.au/sustainable_development

Part of the Construction Engineering Commons

\section{Recommended Citation}

David Cattell. (2012) "An overview of component unit pricing theory" Construction management and economics, 30 (1), 81-92: ISSN 0144-6193.

http://epublications.bond.edu.au/sustainable_development/91 


\section{An overview of component unit pricing (CUP)}

\section{theory}

D.W.Cattell

Bond University, Gold Coast, Queensland, Australia

CUP Theory presents a fresh approach to item pricing, described as the process of distributing the overall price amongst its constituent component items. This theory provides explanation and proof that different distributions of mark-up amongst the items of a project produces different levels of reward for a contractor, whilst exposing them to different degrees of risk. The theory describes the three identified sources of these rewards, namely those of improved cashflow, escalation compensation and valuations of likely variations. In addition, it also provides the first explanation of the three risks involved, namely those described as 'rejection', 'reaction' and of 'being wrong'. In combination, it provides a means by which both the rewards as well as these risks can now be measured given any pricing scenario.

This theory gives effect to fuzzy constraints on the price of each item, providing a scientific basis by which to identify more extreme prices when pursuing more profit and more restrained prices when seeking to reduce risk. Overall, it provides a basis by which to moderate these two objectives in the pursuit of the maximisation of a contractor's utility. A test on a hypothetical project indicates an improvement of more than $150 \%$ on utility, if a contractor applies this theory, compared to if they instead use balanced prices.

Keywords. Bidding, pricing, risk analysis, risk management, mark-up. 


\section{INTRODUCTION}

With unit price contracting in the construction industry, contractors compete on the basis of their bids for whole (composite) projects. These projects comprise many hundreds or thousands of component items, often described in detail in bills of quantities. In the UK and many Commonwealth countries, when contractors compete by way of tendering, it is typical that clients provisionally select the bid from one contractor in preference to all of the other bids. This is often the lowest bidder, although not necessarily so. The client then requests that this contractor submit their priced bills of quantities, as preparation for potentially awarding them the contract. At this stage, the contractor decides their prices for each unit of each of the project's constituent items. This process is known as "item pricing" or "unit pricing".

In other contractual situations, clients may request that all the bids incorporate the details of the item prices along with the overall bids. This offers two advantages to clients: firstly, it prevents any contractor from reacting to any discovery that they have significantly under-bid their competitors by then pricing their items in a manner so as to make their bid unattractive; and secondly, it gives clients information by which to assess all the bids on the basis of all of their item prices rather than only being based on their overall price. Nevertheless, even when armed with this additional information, it has been shown by Skitmore and Cattell (2011) that clients will still have great difficulty trying to judge whether item prices are "loaded" or not. Clients are still largely reliant on the simplicity of the overall bids by which to make a meaningful comparison between contractors.

Significantly, the item prices are not subject to the same competitive forces as the pricing for the overall project. Nevertheless, it is these item prices, rather than the tender price, that will form the basis of all the payments between the client and the contractor, in terms of the contract. Besides being the basis to value the monthly interim payments, they are also used to value the variations to the design of the project (as is very common) and they 
may also be used to determine the quantum of escalation compensation for inflationary increases in costs.

Ordinarily, whilst one might expect a contractor to first price all of the items of a project before adding them together to determine the overall price for the project, it is instead far more likely that it will be done the other way around. Contractors tend to first estimate their item costs, add them together and then decide their overall bid price. After the bid has been decided, they have the choice of many millions of different item price combinations which all summate to this same total. These different pricing scenarios will deliver different benefits to the contractor.

Unbalanced bidding models are mathematical tools for use to determine the optimum choice of these unit prices. In the past, these models have been largely focused on the maximization of the expected profits for a contractor rather than give much consideration to the risks involved. Pursuing high profits is risky: higher profits typically go hand-inhand with a high risk that these may not eventuate. If one ignores risk and focusses only on the hope of high profits, one will typically be led into a direction that might have considerable exposure to the risk that the profits for the project might not arise as hoped. Researchers have, however, often acknowledged that item pricing has risks. Gates (1967), for instance, described the risk as "substantial". For this reason, Stark (1968) advocated the use of a sensitivity analysis. However, despite this, the early researchers made little effort to properly incorporate these risks into their models. Moreover, little has been done to structure these models so that they recognize the inherent nature of the trade-off that exists between unbalanced bidding's contributions to these risks and that of the prospective gains.

All models (such as those suggested by Stark, 1968, 1972, 1974; Teicholz and Ashley, 1978; Diekmann et al., 1982; Tong and Lu, 1992; and Christodoulou, 2008) have otherwise given recognition to risk by vaguely recognising that extremely unusual prices could be problematic and are to be avoided. In effect, whilst these models are typically structured as linear programming models with numerous constraints, they all advocate constraining the prices for each item within lower and upper bounds: seeking to identify 
the price for each of these items that will likely, in combination, generate the highest profits for the project as a whole. Although this does not seem to have been intended, these bounds end up becoming the single most important feature of these models. These bounds give cause, in effect, for all items being priced at either their upper price limit or else their lower price limit, with the exception of only one item. This one remaining item price then serves to ensure that the summation of all the priced items exactly equals the tender price. The effect of these models is therefore reduced to only serving to split all the items into these two subsets: those priced high (and assigned the high prices that are to be chosen arbitrarily by the contractor), and those priced low (and similarly, assigned the contractor's chosen low prices). These models are, therefore, heavily dependent on the contractor's choice of high and low prices and yet their importance does not appear to have been given much consideration when these models were formulated.

Component Unit Pricing (CUP) theory shows that whilst it is heuristically appropriate to constrain the prices for all items, it is not appropriate that these constraints be imposed as fixed, non-negotiable limits. Whilst the latter nature of limit might be considered a 'deterministic' limit, there is typically little to guide their determination and there has been little guidance offered by research as regards how these should be set.

CUP theory furthermore facilitates a basis by which item pricing can be conducted such that the pursuit of profits and the avoidance of risk are treated as objectives that are of equally-important significance. Furthermore, it provides that contractors can manage these two objectives collectively, so that they are able to pursue the optimization of a personalised value of utility, representing a trade-off, best suited to them, between striving for profits whilst, concurrently, avoiding risk. The theory therefore presents a novel perspective on item pricing (as a contributor to both profits and risk) whilst a model is also proposed by which to decide prices in accordance with this new perspective. 


\section{BACKGROUND}

Gates (1959) was the first to identify the role of item pricing (or 'item price loading') as a tendering strategy. This entails allocating different mark-ups to items, providing advantages not available with a uniform mark-up. Further research led to the development of a variety of mathematical techniques by which to optimise this and these have become known as unbalanced bidding models. These are not to be confused with 'bidding models' that are designed to optimise the bid price for a project as a whole.

Common to all the item pricing models is that their objective is to maximize the presentday value of the profit of a project. They all entail the "loading" of the prices of some items (i.e. applying an above-average mark-up), and the (corresponding) "unloading" of the prices of other items. Many contractors are said to avail themselves of this opportunity, according to McCaffer (1979), Green (1986), Kaka and Price (1991) and Kenley (2003).

\section{The effects of item price loading}

For the most part, each item of work within a project has largely different properties when compared to other items. Some items relate to work that has to be done early in the construction schedule; others to activities scheduled later. Many fall within different escalation workgroups in terms of contract price adjustment provisions (should they apply). Some items have an initial quantity attached to them in the bills of quantities that the contractor can be fully confidant will not differ from the final quantity. Some others describe work that is expected to vary in quantity when it is built (being measured as 'provisional'): some of these items may be expected to finally be allocated a higher quantity and others a lower quantity. The final quantities for some items are easier to predict than others, and therefore some of these enjoy a higher degree of confidence as regards their variability than others. Thus, if one considers that each item incorporates 
many different characteristics in different proportions, most items are unique in character. Item price loading seeks to take advantage of these unique attributes of each item by allocating some items higher mark-ups than other items.

Consider the following examples:

- If high prices are allocated to items scheduled for early in the project plan, the contractor will receive larger amounts of money early on. This will aid their initial cash flow for the contract. This is a practice known as 'front-end loading';

- If contractors allocate high prices to items that are scheduled to occur late in the project plan and to those that fall into workgroups that have a high expected escalation, they will be rewarded with additional escalation in compensation for inflation. This could even be more than the cost of escalation to them but, more importantly, will almost certainly be more than if they were to allocate lower prices to such items. This is a practice known as 'back-end loading';

- If contractors are able to predict variations in the contract's design or identify mistakes in the measured quantities, they may take advantage by allocating high prices to items for which they expect the quantity to be adjusted upwards and low prices to items that they expect will be reduced. This is a practice known as 'quantity error exploitation'.

Pursuing any one of these opportunities as examples in isolation is intuitively very simple. However, the reality is a lot more complex when one considers that each single item within a project is typically unique by way of being more complex than simply having only have one such characteristic. Each item cannot simply be described, for instance, as being an 'early' or 'late' item without also having to recognize that it will have other characteristics as well. Each of these characteristics calls for a different treatment as regards item price loading. For instance, a 'late' item might fall into an escalation workgroup that has a high expected rate of escalation. In this instance, it is not obvious whether this item should be allocated a high or low mark-up. The objectives of 
front-end loading would suggest heuristically that 'late' items should be allocated low prices and yet the objectives of back-end loading suggest that a 'late' item in a 'highescalation' workgroup should be allocated a high price. In such an instance, which of these two factors is of greater significance and, therefore, which one of these should have the greater influence on determining the price for this item?

To add further to the complexity, consider that there are many factors that should serve to influence the pricing of each item and that whilst each item is typically unique in terms of these influences, there are typically many hundreds or thousands of these items in a project. Thus, when viewed holistically, with all of the complexity that this has inherent in it, it becomes a lot less obvious how best to pursue the advantages of item price loading. Nevertheless, not only does it remain obvious that these advantages remain intact regardless of this complexity, but also, it is hypothesized that the more complex a project is, the more opportunities there are for item price loading, and the more the advantages of this practice.

The complexity of this problem becomes more intricate and demanding when one considers that contractors are not only potentially able to enjoy greater profits from this manipulation of their prices but that this practice typically also exposes them to additional risk. It is, however, possible that contractors can use unbalanced bidding as a technique by which to reduce their risk. It is a method by which to manage risk as much as it also presents the prospect for increased profits.

\section{OTHER UNBALANCED BIDDING MODELS}

Other unbalanced bidding models commonly have been designed as linear programming models. Linear programming has the restriction that a model may only have one objective function. This restriction appears to have led to the practice in which early item pricing models sought only to maximize either the profit from a project or else the revenue. These models consequently did not incorporate any assessment of the risk for the contractor, even though almost all research in this area has noted that the 'risk' caused by item pricing is a substantial issue. 
Diekmann et al. (1982) chose instead to use quadratic programming and whilst this technique again has the restriction of only one objective function, they proposed an abstract way (facilitated by being able to use a quadratic equation as the objective function) of pursuing a maximization of the expected profit together with a minimization of the risk. They effectively came to combine these two objectives with the use of a constant $(k)$ for which the contractor has to arbitrarily choose a value. Different values of $k$ have the effect of shifting the emphasis of the objective from the maximization of profit to the minimization of risk.

The only other method that has been found to be employed in all of these models by which to control "the risk" is by means of the use of constraints by which to impose arbitrarily chosen (upper and lower) limits on the price of each item. These limits, rather than any other factor, contribute the greatest effect to both the extent to which the profit of a project can be maximized as well as the extent to which the risk can be minimized. However, despite the significance of these limits, it is commonly recommended that they should be decided upon without any scientific or mathematical aid. The use of advanced mathematical programming to refine other aspects of item price loading therefore appears somewhat superfluous as long as the most influential factor, is by comparison, left to be handled relatively crudely.

In effect, the only role that the mathematical techniques have to play is to determine the sequence by which to prioritise which items are to be allocated their upper limit price. This sequence thus identifies the one remaining item that will fall between the set of items given their upper limit prices and the set of items given their lower limit prices. This one remaining item thus serves to satisfy the constraint by which the unbalanced bid is, in summation, equal to the already-determined tender price and it will be the only item price set at neither its upper nor its lower price limits.

Another critical and yet common shortfall of the above-described models relates to their definition of risk. Even in the case of Diekmann et al.'s (1982) model, the only risk factor that was considered and modelled was the risk that the final quantity for some items may be different from that which the contractor estimates. No consideration is 
made of the risks that are generated from 'mis-estimates' of the most appropriate discounting rate, of cost estimates, of changes to the project's schedule, nor any of the other factors that these models simply treat as worthy of a deterministic treatment.

Thus, other unbalanced bidding models suffer from the following shortcomings:

- they are limited in their recognition and management of what constitutes risk,

- none provide a comprehensive (and hence balanced) technique by which to pursue all three of the recognised methods of item price loading (namely, frontend loading, individual rate loading and back-end loading),

- only Diekmann et al.'s (1982) model provides any means by which to quantifiably address the risk vs. return trade-off, but this technique provides a rather abstract device that is not capable of simple, intuitive use, and

- none provide any device by which a contractor can assess the merits and demerits (in terms of both profit and risk) of any adjustments to the upper and lower pricing limits of each individual item - and yet this set of constraints, rather than any other factor, has the greatest influence on the effects of unbalanced bidding. All of the models described above also share in common that they recommend that these limits be arbitrarily decided upon (and regarded thereafter as fixed). In reality, it is highly unlikely that any item should have a maximum or minimum price beyond which a contractor would never submit a price, regardless of the benefits of doing so in terms of increased profit and / or decreased risk. In practical terms, these limits may be regarded as more fuzzy than fixed.

There was a lapse of 15 years (from 1992 to 2007) in which little was proposed in the field by way of new models. Subsequently, research (see Afshar and Amiri, 2008; Christodoulou, 2008) has focussed more on the reduction of risk rather than the pursuit of profit. Mandell and Nylstrom (2011) has confirmed the significance of risk in such models. 


\section{MODELLING A PROJECT'S RISK}

Cattell et al. (2010) determined a new framework to recognize the risks that are generated by way of unbalanced bidding. The latter also provided a basis by which these can be assessed, combined and incorporated into an unbalanced bidding model. It found that these risks can be classified as the risks of rejection, reaction, and of being wrong. Rejection refers to the risk that a client might be so outraged by a contractor's prices that they dispel them and instead choose to work with one of their competitors. The risk of reaction describes clients responding to a contractor's pricing by way of design variations - designing these so as to avoid some items that they might perceive as over-priced, else incorporate more of items that they perceive as being priced attractively low. The risk of being wrong stems from the need for the contractor to make numerous assumptions when pricing a project, a number of which will vary from the eventual reality. If contractors were instead to have the benefit of hindsight and know the truth in advance of their item pricing, they could be expected to price the project differently.

Furthermore, it found that these risks are of two different forms such that they are not easy to add together. The solution has been to use the Value at Risk (VaR) metric (see Manganele and Engle, 2001) which can be used to evaluate all of these risks on the same basis. This then provides a quantified summation of the risks, aside from the previouslydescribed quantified assessment of the expected rewards from each of the alternative pricing scenarios.

\section{[insert Figure 1]}

The above figure shows an example of the output from this nature of risk analysis, showing how the risk is quantifiable for each level of price for each item of the project. The risks of all the items, combined, can then likewise be assessed so that risks generated by any possible pricing scenario can be compared to its expected returns.

Interestingly, the risk generated by item prices is governed by their relationship to market prices, rather than by relationship to the contractor's costs. The mark-up (on the cost) is therefore irrelevant particularly so because each contractor's costs could be quite different to others, whilst their estimate of these costs may be all the more so different. 


\section{MODERN PORTFOLIO THEORY}

Thus, one can assess any item pricing scenario for both the benefits that this is mostlikely to generate, as well as the risks that will be associated with this. Given that a contractor can have this information on-hand, this facilitates that they can seek a scenario that offers them their best-suited trade-off between return and risk. It is logical that some scenarios may offer high returns and high risks, and others low returns and low risks. These could all be considered contenders for the best-suited trade-off, whereas low-return, high-risk scenarios cannot be considered to be attractive as long as there are alternatives.

Modern Portfolio Theory is a technique that is often used in other situations in which returns and risks are being combined and having to be optimised. 


\section{MARKOWITZ}

In 1952, Harry Markowitz wrote a paper (Markowitz, 1952) entitled "Portfolio Selection" that proved to be seminal. He described a new Modern Portfolio Theory ('MPT') that won him the 1990 Nobel Prize of Economics (Markowitz, 1990). This work provided proof of the benefits of diversification.

Prior to the widespread adoption of MPT, the prevailing approach for investors entailed choosing investments that offered the most return for the least amount of risk. Little, if any, regard was given, in any formalised quantitative sense, to the combined effects of such investments. By comparison, Markowitz observed that different investments could be combined - in "portfolios" - such that one could accomplish more than a simple averaging of the constituent investments: that, when combined in a well-formulated combination, the collective return could be more than their average; whilst the combined risk could be less than their average.

Markowitz described the benefits by highlighting the distinction between systemic and investment-specific risks. His work explained the theory behind the intuition that investors benefit from spreading their trust between multiple investments in different industries. When one industry or share may be under threat of prevailing circumstances, another may be booming... Combined, if the underlying variability in the investments is not positively correlated with each other, or if they are to some extent, negatively correlated to each other, the investor will enjoy a less "bumpy ride" from their combined portfolio, or in other words, a less risky one, than if they "had all their eggs in any one basket". By adopting MPT, investors can avoid much of the investment-specific risks even if they cannot avoid the systemic risk that an overall market has in common (across all of the alternative financial instruments).

\section{[insert Figure 2]}


Figure 2 illustrates the case of combining two unrelated investments. Some portfolio / mix of these two investments (shown on the (always) convex curve that links $A$ to $B$ ) will potentially offer a better trade-off between return and risk than either of these investments if partaken of on their own. One example shown is the $50 / 50 \mathrm{mix}$ of these two investments. Assuming that the risks that are inherent within both these investments are not the same, that is, that they are not exactly correlated to each other, this mix of the two together will attract less risk than if they were exactly correlated (the situation shown by the straight, dashed, line linking $A$ to $B$ ). This illustrates the benefits of diversification. The curved line linking $A$ to $B$ is known as the Efficient Frontier. When an investor has the choice of multiple investments, their options can be represented on these two axes as a 'cloud' of opportunity.

\section{[insert Figure 3]}

Figure 3 illustrates this cloud, as well as the Efficient Frontier: representing a subset of the prospective portfolios that share a special property: they offer the most return for that amount of risk. Any rational investor could justify choosing any one of the portfolios that lie on this Efficient Frontier whereas it would be illogical for them to prefer any of the other possibilities that lie within the adjoining cloud.

\section{APPLIED TO UNIT PRICING}

Item pricing also entails deciding between options, some of which have the allure of greater prospective profits, whilst others have the attraction of less risk. The author has identified that the MPT perspective on this trade-off provides a remarkably useful analysis that can also be applied to unit pricing.

There is, however, an interesting distinction between the domains of investing and that of item pricing. In the latter instance, the contractor has no choice that they have to partake of all the members of the set (that is, that they have no choice that the project comprises the items specified) and they have to do so in the same proportion (i.e. that the portfolio mix between them - in as much as this is determined by way of the item quantities - is a dictated constraint). However, in contrast to investments, the contractor does have choice as regards their pricing of these items. When the contractor is doing their unit pricing, 
they are also without any control as regards the overall summation of these prices, but they do, nevertheless, have control as regards the nature and extent to which these can be made to be "unbalanced". By shifting the emphasis around between the constituent components (by assigning them different mark-ups), the contractor can derive greater returns from some combinations than from others; and they can also expose themselves to more risk with some combinations than with others. By contemplating all the alternatives, the contractor can similarly (as do investors) discard any options (such as any low-return, high-risk combinations) that are comparatively "inefficient", and instead focus their attention only on those that offer an "efficient" combination of risk versus likely return. All of the "efficient" pricing scenarios warrant their attention, and combined they offer a spectrum of choice ranging from low-risk, low-return combinations through to high-return, high-risk alternatives.

\section{CUMULATIVE PROSPECT THEORY}

Underlying this application of Modern Portfolio Theory to unbalanced bidding is the assumption that contractors are rational - that they resemble the homo economicus that is a basic assumption made by behavioral economists (Persky, 1995). In other words, they are averse to taking additional risks without the prospect of an adequate increase in reward. This assumption helps to identify the efficient set of item pricing combinations but it does not help with identifying any preference for any single one of these combinations within this set. Some contractors can rationally choose a high-return / high-risk option, whilst others may rationally justify a preference for another choice down at the low-return / low-risk end of the spectrum. Any choice of an efficient pricing combination is rational, whereas the choice of any other combination is not.

In the general field of financial economics, these nature of decisions are typically dealt with by way of utility theory. A recent version of utility theory, namely Cumulative Prospect Theory ('CPT') (Tversky and Kahneman, 1992) serves to further reduce the set of efficient options to the extent that a contractor can identify, from amongst these, the one pricing combination that will optimally suit their risk profile. 
CPT provides a method by which a contractor could identify their optimum unit pricing taking into account the effects of item prices on both the expected return that a contractor will enjoy as well as their risks. This model takes account of the contractor's appetite for risk and finds the solution that they will find 'most satisfying' given recognition of their psychology as regards tackling projects with various prospects of returns and risks.

\section{SOFTWARE FOR TESTING THE MODEL}

Software was written to test the theory on a hypothetical project. The software was written in Java as an application of Monte Carlo simulation. It was designed to be more efficient than being purely random, considering the vast number of possible item price combinations that are possible in a typical project. As a result, the MCS process is guided by a novel hybrid use of a range of techniques that have been described as artificial intelligence, genetic computing and fuzzy logic. This system is able to identify the quasi-optimum item pricing scenario for a project. The full source code for this system is available in Cattell (2011).

\section{TESTING THE MODEL}

Testing the system shows that the early stages are characterised by big steps in improvement in the pricing, and the improvements become progressively smaller, and less frequent, as it finds it becomes more and more difficult to incrementally continually improve on its past discoveries. This is shown in Figure 4 below where it is also shown that the system becomes a lot 'smarter' around iteration number 1000. Up until the $1000^{\text {th }}$ iteration, the system explores new pricing scenarios on a more random basis and in the process gathers intelligence by which to subsequently be able to improve upon its performance. After every 1000 iterations, the system evolves to the next 'generation', using its intelligence to become progressively 'smarter': predicting that most possible pricing scenarios won't be 'efficient' and that it will be a waste of processing time if these were to be fully assessed. At the same time, the system does recognise that its 
intelligence is dependent not only on those attempts to 'push the boundary forward' as regards pursuing higher values of utility, but also it has much to learn from the experience of many of the other attempts. The system is thus designed to make a number of its efforts aimed at being a serious attempt at an overall improvement in the project's utility, along with many other scenarios that are believed likely to lead to a better understanding of the dynamics involved. This reflects in the results shown in Figure 4, where many of the results are found clustered near the upper edge of the envelope of the utility achieved, along with a spread of others that are processed in the hope that their role is that of gathering intelligence aimed at leading to a better performance in the subsequent 'generations' being explored.

\section{[insert Figure 4]}

Figure 5 below shows how the system progresses as regards increasing the return from the project, whilst seeking to bring down the risk. Around iteration 60,000 it can be seen how the system has found that it has gathered sufficient data as regards how individual item's prices deliver utility, that the challenge thereafter becomes more focussed on using this intelligence by which to explore the multitude of scenarios by which these prices can be assembled, all of which must satisfy the constraint that overall they must add up to the same project tender price. Once the objective of the system has made this shift, it is shown how it becomes far more effective at finding solutions that offer combinations of better rewards and lesser risks. Notice, though, that in order for the system to have reached this stage, it is dependent on the intelligence that is gathered from the earlier stages. Notice too that the system finds that it manages to 'squeeze' more utility from a project largely due to being able to progressively reduce the risk, whilst keeping the 'rewards' roughly constant. The Y-axis on the left-hand-side shows the expected NPV being generated from the pricing scenario (as the metric of 'rewards') whilst on the righthand-side the axis shows a metric of the corresponding VaR.

\section{[insert Figure 5]}


The test shows the software succeeding as regards identifying a combination of item prices that is expected to generate a profit with an expected mean of around $150 \%$ more than that which would be accomplished by way of a balanced bid. The contractor stands to make a present-day profit that has a mean of $\$ 187,391$ rather than $\$ 76,109$, as shown in Figure 6 below (in both instances taking account of an assumption that the profits will be eroded by way of a "winner's curse" by which the eventual actual costs will be $3 \%$ more than those estimated - hypothesised as being inevitable in a competitive tender environment and hence necessary for incorporation into the model).

\section{[insert Figure 6]}

Notice that more profit could be accomplished if the contractor were willing to accept more risk. In this instance, these prices reflect the compromise between profitability and risk that the (hypothetical) contractor (in question) feels to be most satisfying to them.

It is also noteworthy that the prices (listed in Cattell, 2011) that the system has generated are constrained within the minimum and maximum bounds provided as input by the contractor, with the result that the prices are likely to appear as relatively 'normal' by comparison to what the contractor has observed as being prevalent in the industry. The prices fall somewhere within the limits set, rather than fall exactly on these limits.

Taking account of the three risks identified, and seeking to avoid these, largely leads to prices that resemble those prevalent amongst the competition in the industry. This supports the heuristic that prices that 'blend' in more with their surrounds will less likely lead to being considered objectionable. Industry prices for typical items nevertheless present themselves as a range rather than as a singular (universally-accepted) price. CUP Theory presents an interesting basis by which prices are effectively governed within these ranges: pulling them inwards, by way of a centripetal force, towards the centre (of what the industry has grown accustomed to) when a contractor is seeking to lessen their risk; and pulling them apart, by way of a centrifugal force, out towards the (fuzzy) edges of these ranges, when a contractor is willing to take more risk in pursuit of more profits. The theory, furthermore, presents a scientific basis by which to decide the extent to which 
individual prices should fall within their individual 'ranges', given the contractor's attitude to risk. Also, it provides a basis by which to decide this for each of the thousands of items within a project - whilst taking them all into account in the manner in which they combine - such that items that promise to deliver a greater utility from more extreme pricing are prioritised over items that are governed by greater degrees of scrutiny.

\section{CONCLUSION}

This new theory has not yet been tested in practice but a test of some hypothetical data has been successful at providing an initial validation of its application. The hypothetical test has shown that a contractor could enjoy a substantial increase in profitability without excessively exposing themselves to risk. Furthermore, the theory proposes a methodology for contractors by which these dual, and opposing, objectives are managed in accordance with their assessed attitude to risk, presenting them with a balance between the two that would appear best suited to them. The method also gives them the opportunity to review their risk profile and choose to accept more risk or seek to avoid risk, being able to do so on a scientific basis.

The theory is also of value at providing a basis by which projects' items can be priced on a consistent, scientific and rational basis, governed by managerial parameters that can ensure that the decision-making involved is reasoned and reliable.

This theory also provides proof that 'unbalanced bidding' need not be excessive in order to be significantly valuable. Unbalanced bidding is often criticized (for instance by Arditi and Chotibhong, 2009) for reason that it is felt that it amounts to an unethical abuse of the system by a contractor. Tests, however, show that unbalanced bidding can be subtle, within the bounds of what is likely to be deemed 'acceptable' by all stakeholders, and yet still able to contribute substantial benefits for contractors. It is suggested that the nature of pricing that this model has identified in this instance, is unlikely to be perceived (Skitmore and Cattell, 2011) by any client as being excessively 'loaded'. 
This research has established a scientific basis for more-effective, better-informed unit pricing by contractors. It has (1) extended the present theoretical foundation for component unit pricing, (2) in particular, by way of gaining better insight into both the risks as well as the rewards generated from unit pricing. It has also (3) provided a basis for a new mathematical model that quantifies both the risks and rewards of unit pricing. This facilitates the decision being made on unit prices that will give effect to a measured and reasoned compromise between the pursuit of rewards, together with the restraint required to avoid excessive risk (as suited to the circumstance and psychology of a particular contractor). In effect, this new theory provides the mechanism by which prices are governed by fuzzy constraints. These are heuristically better suited than fixed upper and lower bounds, particularly so because, as yet, there appears to be little basis by which to decide the quantum of these bounds. Further concern, as regards the prior methods, is the significance attributed to these bounds. CUP Theory instead gives contractors control of a rational mechanism by which to determine their optimal pricing points within these fuzzy bounds. Furthermore, this theory ensures that these prices will inevitably appear 'normal' relative to market conditions. Additional research is called for, to test this new theory in practice, going beyond the success of the initial hypothetical test. 


\section{REFERENCES}

Afshar, A. and Amiri, H. (2008) A fuzzy-based model for unbalanced bidding in construction. First International Conference on Construction in Developing Countries, August 4-5, Karachi, Pakistan. Available at http://www.neduet.edu.pk/Civil/ICCIDC-I/Complete\%20Proceedings.rar\# page $=68$ [accessed 8th April, 2009]

Arditi, D. and Chotibhong, R. (2009) Detection and prevention of unbalanced bids. Construction Management and Economics, 27(8), 721-732.

Ashley, D.B. and Teicholz, P.M. (1977) Pre-estimate cash flow analysis. Journal of the Construction Division, American Society of Civil Engineers, Proc. Paper 13213, 103(C03), 369-379.

Cattell, D.W. (2011) Construction item pricing for more profit and less risk. Cape Town: UCT Press.

Cattell, D.W., Bowen, P.A. and Kaka, A.P. (2010) The risks of unbalanced bidding. Construction Management and Economics, 28(4), 333-344.

Christodoulou, S.E. (2008) A bid-unbalancing method for lowering a contractor's financial risk. Construction Management and Economics, 26, 1291-1302.

Diekmann, J.E., Mayer, R.H. Jr. and Stark, R.M. (1982) Coping with uncertainty in unit price contracting. Journal of the Construction Division, American Society of Civil Engineers, 108(C03), 379-389.

Gates, M. (1959) Aspects of competitive bidding. Annual Report, Connecticut Society of Civil Engineers.

Gates, M. (1967) Bidding strategies and probabilities. Journal of the Construction Division, American Society of Civil Engineers, 93(C01), Proc paper 5159, 75-107.

Green, S.D. (1986) The unbalancing of tenders. MSc dissertation, Department of Building, Heriot-Watt University. 
Kaka, A.P. and Price, A.D.F. (1991) Net cashflow models: Are they reliable?

Construction Management and Economics, 9(3), 291-308.

Kenley, R. (2003) Financing Construction: Cash flows and cash farming. London, Spon Press.

Mandell, S. and Nylstrom, J. (2011) Endogenous risk in unbalanced bidding. Proceedings of Management and Innovation for a Sustainable Built Environment, 20-23 June 2011, Amsterdam, The Netherlands.

Manganele, S. and Engle, R.F. (2001) Value at risk models in finance. European Central Bank: Working Paper Series, 75, August.

Markowitz, H.M. (1952) Portfolio selection. Journal of Finance, 7(1), 77-91.

Markowitz, H.M. (1990) Foundations of portfolio theory. Nobel lectures in economic sciences 1981-1990. Ed. Karl-Göran Mäler, World Scientific, 279-288.

McCaffer, R. (1979). Cash flow forecasting. Quantity Surveying, August, 22-26.

Persky, J. (1995) Retrospectives: the ethology of Homo Economicus. The Journal of Economic Perspectives, 9(2), 221-231.

Skitmore, R.M. and Cattell, D.W. (2011) On being balanced in an unbalanced world. Forthcoming Journal of the operational research society.

Stark, R.M. (1968) Unbalanced bidding models - theory. American Society of Civil Engineers, Journal of the Construction Division, 94(C02), 197-209.

Stark, R.M. (1972) Unbalancing of tenders. Proceedings of the Institute of Civil Engineers, Technical Note 59, 51, 391-392.

Stark, R.M. (1974) Unbalanced highway contract tendering. Operational Research Quarterly, 25(3), 373-388.

Teicholz, P.M. and Ashley, D.B. (1978) Optimal bid prices for unit price contract. American Society of Civil Engineers, Journal of the Construction Division, 104(1), 57-67.

Tong, Y. and Lu, Y. (1992) Unbalanced bidding on contracts with variation trends in client-provided quantities. Construction Management and Economics, 10, 69-80. 
Tversky, A. and Kahneman, D. (1992) Advances in prospect theory: cumulative representation of uncertainty. Journal of Risk and Uncertainty, 5, 297-323. 
